\title{
Los dilemas de la democracia en la república restaurada
}

\author{
Nicolás Cárdenas García y \\ Lucila Rojas Olvera \\ UAM-XOCHIMILCO
}

\section{INTRODUCCIÓN}

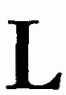

a historia independiente de México no ha sido pródiga en periodos de vida democrática. De hecho, existe un cierto consenso acerca de que sólo ha tenido dos experiencias de ese tipo: la república restaurada y el gobierno de Madero. ${ }^{1}$ La primera de ellas, sin embargo, condujo a la dictadura de Díaz. ¿Cómo puede explicarse tal desenlace?

Enrique Krauze ensaya una respuesta a ese fracaso: "la república había sido una edificación en el vacio", faltaban los cimientos de una eco-

1 Krauze, Democracia, 1990 , pp. 47-48. Una opinión contraria sobre la república restaurada en González Casanova, Estado, 1985, pp. 101. 102. nomía vigorosa. ${ }^{2}$ François-Xavier Guerra ofrece una explicación similar: el ideal democrático no podía ser más que ficción, en tanto no se correspondiera con una sociedad tradicional. Entre la realidad social y el proyecto de los liberales había un abismo. ${ }^{3}$ Pero mientras Krauze acepta que en esa etapa sí hubo una práctica política de las instituciones liberales, Guerra simplemente niega que haya diferencias de fondo entre la república restaurada y el porfiriato, ya que sólo fueron momentos distintos de las relaciones entre la elite y los caudillos. ${ }^{4}$

En este artículo argumentamos una respuesta más matizada dentro del te-

\footnotetext{
2 Krauze, Democracia, p. 47.

3 Guerra, México, 1988, t. I, pp. 193-196.

4 Ibid., p. 52.
} 
rreno de la propia política. Es cierto que uno de los rasgos distintivos del largo régimen porfirista,' la centralización de poder en el ejecutivo, tuvo antecedentes directos en los gobiernos de Juárez y Lerdo, ${ }^{5}$ pero también es verdad que otras prácticas esenciales de la vida democrática liberal -el respeto a la oposición, la libertad de prensa, la independencia de poderes, el reconocimiento gubernamental de errores y su consiguiente rectifcación- diferencian radicalmente ambos periodos, pues el porfirismo poco a poco, pero con firmeza, va prescindiendo de lo anterior.

Hacer esta diferenciación es tanto más necesario si aceptamos que en lo referente al proyecto económico "el régimen de Díaz no traicionó a la ideología liberal". 6 Su obra de modernización convirtió en realidad muchos de los propósitos del 57 y la reforma: movilización de las propiedades de corporaciones para consolidar la propiedad privada, libertad de industria, un proteccionismo limitado, estímulos y concesiones al capital privado, apertura al capital extranjero, establecimiento de comunicaciones modernas. Se trató de un proceso tan abierto a la iniciativa individual, que incluso conservadores vencidos pudieron incorporarse. ${ }^{7}$

El proyecto económico triunfó a costa de la democracia. Nuestra in-

5 Opinión que entre otros ha expresado Romana Falcón, en "Logros", 1989, pp. 130-131.

6 Cita de la Introducción de Staples, Dominio, 1989, p. 12.

7 Véase Covo, Ideas, 1983 , pp. 406-466; Verduzco, "Zamora", 1983, pp. 68-69; Walker, Parentesco, 1991, p. 275. tención es mostrar, mediante un análisis más detallado de la lucha política del periodo, qué tipo de democracia perdió el país, lo que además puede ilustrar las tensiones entre la necesidad de fortalecer al ejecutivo y el profundo respeto a los valores liberales.

\section{LA CONVOCATORIA DEL 14 DE AGOSTO DE 1867}

La aparente paradoja señalada por Cosío Villegas acerca de que Juárez gobernaba fuera de la Constitución, pero dentro de la ley, ${ }^{8}$ se ve plenamente ilustrada con la convocatoria a elecciones federales de 1867 , expedida por el presidente el 14 de agosto de ese año. Su ambivalencia marcó el tono político de la república restaurada, pues si bien era fruto de las facultades extraordinarias concedidas al ejecutivo y por ello un acto legítimo, al mismo tiempo contenía propuestas y métodos contradictorios con la Constitución de 1857. Esto fue bastante sorpresivo, si tenemos en cuenta la opinión unánime de que el texto constitucional era para los liberales triunfantes un documento sagrado, intocable, que después de una larga lucha sería por fin puesto en vigor.?

La convocatoria comenzaba por recordar el decreto del 8 de noviembre de 1865, mediante el cual Juárez había prorrogado el término de su mandato presidencial hasta que la conclusión de la guerra permitiera celebrar elec431.

8 Cosío Villegas, República, 1984, pp. 430-

9 Ibid., pp. 67 y 459; Rabasa, Constitución, 1956, p. 29; Scholes, Política, 1972, p. 164. 
ciones. Proseguía con una protesta de lealtad a la Constitución, la cual "reconoce y sanciona ella misma la posibilidad de adicionarla o reformarla por la voluntad nacional", y después pasaba a los considerandos más delicados. Vale la pena transcribir el cuarto: ${ }^{10}$

Que si esto no deberá hacerse en tiempos ordinarios, sino por los medios que establece la misma Constitución, sin embargo, por la experiencia adquirida en años anteriores, y en un caso tan excepcional como el de la grave crisis que acaba de pasar la nación, parece oportuna hacer una especial apelación al pueblo, para que en el acto de elegir a sus representantes, exprese su libre y soberana voluntad, sobre si quiere auto. rizar al próximo Congreso de la Unión, para que pueda adicionar o reformar la Constitución federal en algunos puntos determinados, que pueden ser de muy urgente interés para afianzar la paz $y$ consolidar las instituciones, por referirse al equilibrio de los poderes supremos de la unión, y al ejercicio normal de sus funciones, después de consumada la reforma social.

De este modo la convocatoria introducía la apelación directa al pueblo (el plebiscito) como mecanismo para reformar la Constitución, a despecho de que en ella no se contemplaba esa modalidad.

Por añadidura, esa apelación se hacía extensiva para la reforma de las constituciones estatales, y de paso se legitimaba la erección de Coahuila como estado independiente. Fi-

10 La convocatoria íntegra puede verse en Cosmes, Historia, 1901, pp. 21-33. nalmente, se señalaba la necesidad de abrir lo más posible el ejercicio de la soberanía popular en la elección de sus representantes.

Los artículos reglamentarios precisaban con detalle estas propuestas. El noveno contemplaba las cinco reformas constitucionales objeto de la apelación:

Primero. Que el poder legislativo de la federación se deposite en las dos cámaras, fijándose y distribuyéndose entre ellas las atribuciones del poder legislativo.

Segundo. Que el presidente de la república tenga facultad de poner voto suspensivo a las primeras resoluciones del poder legislativo, para que no se puedan reproducir sino por dos tercios de votos de la Cámara o cámaras en que se deposite el poder legislativo.

Tercero. Que las relaciones entre los poderes legislativo y ejecutivo, o los informes que el segundo tenga que dar al primero, no sean verbales, sino por escrito, fijándose si serán directamente del presidente de la república o de los secretarios del despacho.

Cuarto. Que la diputación o fracción del Congreso que quede funcionando tenga restricciones para convocar al Congreso a sesiones extraordinarias.

Quinto. Que se determine el modo de proveer a la sustitución provisional del poder ejecutivo, en caso de faltar a la vez el presidente de la república y el presidente de la Corte Suprema de Justicia.

El artículo 14 señalaba ambiguamente que el Congreso se declararía autorizado para hacer las reformas si del cómputo "resultase por la afirma- 
tiva la mayoría absoluta del número total de votos emitidos sobre las reformas". Los restantes se ocupaban de los mecanismos concretos del proceso, así como de la extensión del derecho de voto -para incluir a los eclesiásticos-y declaraba prescindible el derecho de residencia para ser elegido diputado.

La idea central de las reformas, que era la de procurar una nueva relación entre los poderes legislativo y ejecutivo, favorable al segundo, es decir, la intención de darle mayor poder al presidente en detrimento de la Cámara, atacaba de modo directo un punto central de la Constitución. Era tanto como reconocer que el modelo de gobierno ahí establecido era imposible de ponerse en vigor en las condiciones de la república restaurada, mismas que exigían una concentración del poder para hacer frente a las tareas de pacificación y reconstrucción nacional.

La reacción que produjo la convocatoria fue impresionante, y se orientó sobre todo a la crítica del mecanismo propuesto para llevar a cabo las reformas. Cosmes resume bien la situación cuando dice:

Fue tal la agitación producida por la convocatoria que hubo momentos en los que se temió con seriedad una revolución: los empleados de ideas exaltadas renunciaban sus puestos, lo cual en un país como México, devorado por la empleomanía, es cosa que marca el summum de la indignación pública; los principales jefes del ejército murmuraban contra el gobierno; los ayuntamientos de ciudades de importancia, algunas de primer orden en el país, como Puebla y Querétaro, prometian no obedecer, al presidir las elecciones, lo prescrito por la convocatoria, y no atenerse más que a las disposiciones de la ley electoral; y por último, el gobernador del estado más poderoso de la república, por la densidad de su población en un pequeño territorio y su riqueza minera y agrícola, el estado de Guanajuato, manifest 6 al gobierno que no ejecutaría la ley del 14 de agosto, en la parte relativa a las reformas propuestas. ${ }^{11}$

Parece claro, dada la abundante evidencia, que Juárez y Lerdo no valoraron justamente el momento político para hacer la propuesta. Suponían que después del triunfo, y ante la inminente victoria de Juárez como can. didato presidencial, bastaría su nombre para justificar cualquier medida, hasta intentar reformar una Constitución que sólo rigió brevemente al país en 1861. Sin embargo, habia en la experiencia reciente razones que los empujaban a ello.

En el Plan de Ayutla el ejecutivo quedó subordinado al próximo Congreso, mediante la facultad de revisar sus actos. De esta manera los diputados constituyentes se vieron directamente inmiscuidos en la práctica gubernamental, y chocaron repetidamente con Comonfort. ${ }^{12}$ La misma Cámara se encargó de elevar a rango constitucional esa primacía. Con el recuerdo de Santa Anna pesando sobre sus deliberaciones, vio en el ejecutivo el peligro de la tiranía, de un despo-

11 Ibid., p. 59.

12 Covo, Ideas, 1983, pp. 502-503. 
tismo sin freno, por lo que fue supeditado al legislativo, quien a través del uso de las dispensas de trámite, se constituyó en un "poder formidable por su extensión y peligrosísimo por su rapidez de obrar". Justamente por ello podía ser calificado de Convención, y no de Congreso, según Rabasa. ${ }^{13}$

A pesar de las conflictivas relaciones entre Comonfort y el Congreso, éste le concedió facultades extraordinarias una vez conocido su gabinete, que incluía a Juárez como ministro de Justicia y por tanto vicepresidente. ${ }^{14}$ De cualquier modo, en sus apuntes Comonfort insistía en la necesidad de extender las facultades del poder ejecutivo federal y de concederle el veto sobre las resoluciones de la Cámara. Además planteaba la elección directa universal del presidente, quien de esta manera no tendría que ser aprobado por la Cámara, y derivaría su legitimidad del pueblo. Asimismo, proponía la independencia e inmovilidad del poder judicial. ${ }^{15}$

Esa experiencia previno a Juárez de las dificultades que tendría con el Congreso en el futuro, pero éstas rebasaron cualquier previsión. En la medida en que, para esa época, los liberales ya no componían un conjunto único, con pleno acuerdo sobre la naturaleza del proyecto político a seguir, y las distintas corrientes estaban representadas en la Cámara -con un ligero predominio radical-, el presidente Juárez, más bien representante de los mode-

13 Rabasa, Constitucion, 1956, p. 85.

14 Cadenhead, Juarez, 1975, p. 55; Covo, Ideas, 1983, p. 507.

15 Rabasa, Constitución, 1956, pp. 91-92. rados, tenía que maniobrar para constituir una fuerza propia en el legislativo. En caso de no hacerlo, estaría a merced del Congreso e inmovilizado. Esto fue evidente después de su regreso triunfal a la ciudad de México en 1861.

En las elecciones de 1861 no obstante, Juárez triunfó con 5289 votos contra 1989 de Miguel Lerdo (ya muerto para el cómputo) y 1846 de González Ortega; contaba con tal oposición en el Congreso que el dictamen según el cual se le declaraba electo por mayoría, fue aprobado por sólo 61 contra 55 sufragios. Los esfuerzos de la oposición se orientaron a tratar de llevar a una elección entre Juárez y González Ortega, y cuando esto fracasó, propusieron la creación de un Comité de Seguridad Pública que contrarrestara las facultades del presidente. Después intentaron que se integrara un triunvirato para sustituir a Juárez. Finalmente sólo obtuvieron que el Congreso eligiera a González Ortega presidente interino de la Suprema Corte, con lo que se convertía en el sucesor posible de Juárez. ${ }^{16}$

Ese mismo Congreso generó el problema de estabilidad más grave a Juárez en vísperas de la invasión extranjera. En septiembre de 1861, 51 diputados exigieron su renuncia. Por fortuna, los leales al ejecutivo reunieron ese mismo día 52 firmas de otros tantos parlamentarios que le reiteraban su confianza. Detrás de la maniobra parecía encontrarse el general

16 Cadenhead, Juarez, 1975, pp. 80-81; Scholes, Política, 1972, pp. 105-106. 
González Ortega, puesto que de renunciar Juárez, él se convertiría en presidente interino. ${ }^{17}$

Todavía fresco este asunto, se suscitó un interesante debate entre Manuel Doblado y Juárez -quien lo había llamado para fortalecer el gabinetesobre el carácter de los secretarios de Estado. Doblado estableció como condiciones para aceptar su integración, la posibilidad de elegir a los restantes ministros, así como completa libertad de acción, a semejanza de los sistemas parlamentarios europeos. La respuesta de Juárez fue una negativa absoluta, bajo el argumento de que al ser responsabilidad del presidente la designación de sus ministros, era también responsable de sus políticas. A fin de cuentas la posición de Juárez prevaleció en esa disputa. ${ }^{18}$

La propuesta de revisar el mecanismo para cubrir una eventual falta de presidente tampoco era gratuita. Derivaba de la experiencia de 1865, año en que terminaba el periodo para el cual fue elegido Juárez. En plena guerra contra los imperialistas, los reformistas tuvieron que enfrentar el problema del término del mandato presidencial. Por un lado, no era claro si finalizaba en mayo o en diciembre, $y$ por otro, las ambiciones de González Ortega se habían manifestado claramente en los años anteriores, y se temía que estuviera dispuesto a nego-

17 Cadenhead, Juarez, 1975, p. 85; Scholes, Política, 1972, p. 118.

18 Cadenhead, Juárez, 1975, pp. 85-86; Scholes, Politica, 1972, pp. 120-121.

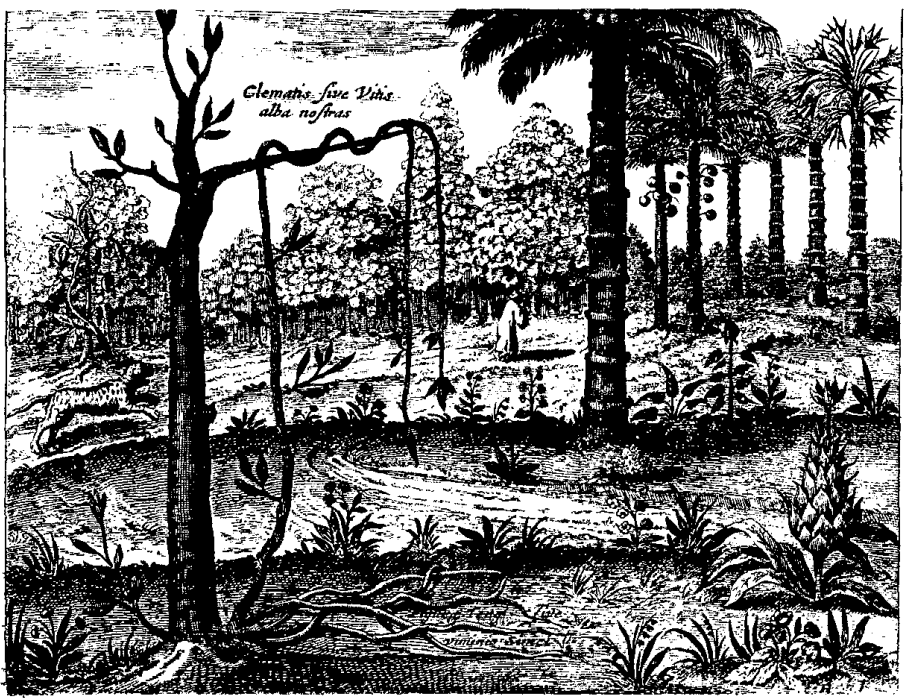


ciar con Maximiliano. Por ello, casi expirado el plaze dentro del cual su situación era plausiblemente legal, el 8 de noviembre Juárez resolvió el problema mediante dos decretos, justificados por los poderes extraordinarios recibidos del Congreso en mayo de 1863.

El primero ampliaba su propio periodo de ejercicio así como el del presidente de la Suprema Corte, hasta que fuera posible realizar nuevas elecciones. El segundo declaraba que en tanto González Ortega había perma. necido en un país extranjero (Estados Unidos) sin permiso o comisión del gobierno, a su regreso tendría que sujetarse a dos procesos judiciales. Uno calificaría si había desertado de la presidencia de la Suprema Corte, y el otro ventilaría el abandono del mando de sus tropas. Además, facultaba al gobierno a nombrar un nuevo titular del poder judicial, quien sería el primero en la línea de sucesión. Aun cuando Juárez no estaba totalmente en lo cierto, ya que sí se había concedido a González Ortega permiso para ir a Estados Unidos, las protestas del general no tuvieron mayor apoyo, y cuando regresó al año siguiente pronto fue encarcelado. La mayoría de los liberales mantuvieron su lealtad a Juárez, y por tanto la unidad necesaria para continuar la lucha frente a los franceses y los conservadores. ${ }^{19}$

Conocidos esos antecedentes, podemos entonces comprender la preocupación de Juárez por dar un cauce rápido a las reformas. La escasa expe-

19 Cadenhead, Juárez, 1975, pp. 104-106; Scholes, Politica, 1972, pp. 154-157. riencia de gobierno en términos constitucionales había tendido a mantener un ejecutivo débil cuando las condiciones de guerra civil e intervención requerían fuerza y unidad. Sin embargo, también es cierto que gracias a la concesión de facultades extraordinarias de que disfrutó entre 1858 y 1861 , y entre 1863 y 1867 , el ejecutivo concentró y usó con libertad más poder del que constitucionalmente le correspondía. 20

Lo que a Juárez y Lerdo les parecía muy claro, la necesidad de reforzar al ejecutivo, no contaba con la sim. patía de buena parte de los liberales. A pesar de ello, sus críticas se dirigieron al mecanismo propuesto para llevarlo a cabo, antes que a su contenido. Probablemente había algunos partidarios de las reformas, pero en tanto desaprobaban el mecanismo utilizado, el proyecto sufrió un rechazo general, orientado principalmente a la persona de Lerdo. Tan grave era la situación que Juárez mismo tuvo que salir en defensa del decreto, con sus declaraciones de agosto 22 . En ellas invocaba sus antecedentes y su conducta respetuosa de la voluntad nacional, para afirmar que todas las reformas hechas por su gobierno habían tenido el fin de "desarrollar y perfeccionar los principios de la Constitución de la república", y que ese mismo espíritu alentaba las controvertidas propuestas, las cuales expresaban sus "intimas convicciones". Con ello respondía a las críticas a Lerdo y asumía la responsabilidad del documento.

20 Rabasa, Constitución, 1956, pp. 98-100. 
Se ha pretendido -decía textualmente Juárez- distinguir mis propias opiniones de las de mis consejeros oficiales. Los antiguos consideraban haber cumplido su deber patriótico, y quisieron separarse del gobierno al salir de San Luis para esta ciudad. Ahora también han pedido separarse, ellos y los nuevamente nombrados, para dejarme en completa libertad de obrar; pero yo no he creído que debía aceptar su dimisión, porque no ha habido desacuerdo de opinión, y porque estoy satisfecho de la rectitud y lealtad de sus intenciones. ${ }^{21}$

Respaldado por esa declaración presidencial, Lerdo envió una circular a los gobernadores justificando la propuesta. En ella defendía con vigor la idea de fortalecer al ejecutivo frente al despotismo de la Convención creada por el constituyente, justificaba el plebiscito por las condiciones extraordinarias del país, recién salido de "una crisis terrible y dolorosa", y defendía el postulado de que finalmente era una apelación a la voluntad general del pueblo, en quien residía la soberanía. ${ }^{22}$

Como quiera que las declaraciones del presidente y de Lerdo no apaciguaron los caldeados ánimos, se tuvo que recurrir a otros expedientes para calmar la tormenta. Al gobernador de Guanajuato, León Guzmán, quien se negó a publicar íntegramente la convocatoria, se le notificó la terminación

21 El comunicado está reproducido en Cosmes, Historia, 1901, pp. 33-37. La cita es de la p. 36.

22 Cosmes, Historia, 1901, pp. 38-44; Rabasa, Constituctón, 1956, p. 107. de su encargo, y se le ordenó entregar el gobierno estatal al general Florencio Antillón, así como presentarse en la ciudad de México. Los términos del comunicado de Lerdo al gobernador fueron por demás duros.

Tiene usted -le reprochaba Lerdo a Guzmán-, como ciudadano, un perfecto derecho de opinar según lo crea conveniente. Ha tenido usted como libre ciudadano, el derecho de renunciar el cargo que el gobierno le había confiado: no ha tenido usted el derecho de desobedecer sus disposiciones.

[...] Desde ese momento, sólo podía usted figurar como un gobernador rebelde contra el gobiemo, que lo nombró, y como un comandante militar nombrado por el gobierno y pronunciado contra el mismo. 23

Aunque Cosmes se excede al señalar que la convocatoria fue la causa principal de la división de los liberales, lo cierto es que parece haber creado un clima propicio para la formación de un grupo o partido porfirista (constitucionalista), en la medida en que Díaz supo mostrar su desacuerdo con los procedimientos anticonstitucionales de Juárez y Lerdo. En todo caso el debate permitió que cristalizaran esas divergencias. ${ }^{24}$

Juárez no dejó de advertir que su popularidad había disminuido a raíz de la convocatoria y decidió protegerse reconociendo la justeza de los argumentos opositores. El día de la

23 Ibid, p. 62.

24 Ibid., pp. 45 y 51; García Granados, Historia, 1923, pp. 57-59; Ceballos, Aurora, 1907 , p. 32. 
instalación del Congreso, el 8 de diciembre de 1867 , retiró la propuesta, gesto que fue muy bien recibido por la opinión pública. En su discurso reinvindicaba como mérito del gobierno la amplia libertad que hubo en el periodo preelectoral, y reconocía las críticas recibidas, de tal modo que aun con la presunción de que la mayoría del pueblo había votado ya sea en contra o a favor de las reformas, prefería retirarlas para evitar que "pudieran suscitarse cuestiones o dudas" que difiriesen su resolución, ya que se había escogido apelar al voto general por la rapidez del procedimiento.

La convicción que ha tenido y tiene el gobierno -explicaba con dignidad Juárez-de que son necesarias y urgentes, le hace preferir que se prescinda de la cuestión de forma esperando de otro modo se pueda llegar más pronto a resolverlas. Por esto en lugar de pedir que se haga el escrutinio, ha acordado el gobierno someter los puntos propuestos de reforma a la sabiduría del Congreso, para que pueda dictaminar acerca de ellos, conforme a las reglas establecidas en la Constitución. Con este fin se presentará desde luego la iniciativa correspondiente. 25

Antes de conocerse el resultado de la elección presidencial, Juárez cumplió con su promesa. Envió un nuevo proyecto el 13 de diciembre, que re-

${ }^{25}$ En esa misma oportunidad, el presidente devolvía las facultades extraordinarias que había recibido en 1863 , aun cuando estaba autorizado a ejercerlas 30 días más. El discurso de Juárez puede consultarse en Ceballos, Aurora, 1907, pp. 314-319; la cita es de la p. 318. petía las mismas cinco propuestas. ${ }^{26}$ Pero éste no fue tratado con apresuramiento por la Cámara, de tal modo que hasta abril de 1870 se pudo votar en lo general, sin que pudieran discutirse los artículos en lo particular. Nunca pudo ver realizadas las reformas.

E1 18 de diciembre de 1867 se declaraba presidente electo a Juárez para su tercer periodo, y poco después presidente de la Suprema Corte a Sebastián Lerdo. Con ello parecía terminado este episodio, pero la minoría porfirista de la Cámara, encabezada por Manuel María de Zamacona, impuso una declaración dada a conocer el 8 de enero de 1868, donde se llamaba al cumplimiento cabal de la Constitución.

El Congreso -decían los diputados- excita encarecidamente a los ciudadanos todos, y particularmente a los investidos por el pueblo de cualquier autoridad, a la fiel y escrupulosa observancia de la Constitución. El Congreso por su parte, se ha trazado ya esa línea invariable de conducta, y se ha acordado no prescindir por ninguna consideración de las prescripciones constitucionales, teniendo en cuenta que si se anhelan saludables reformas, ha de quererse también que tengan todo el prestigio y toda la fuerza de la legalidad. En consecuencia, se ha abstenido de computar los votos emitidos conforme a la convocatoria de 14 de agosto sobre reformas constitucionales. ${ }^{27}$

26 Cosmes, Historia, 1901, p. 99.

27 El proyecto fue presentado por José Alas y Nicolás Lemus, y la comisión redactora la formaron Zarco, Rafael Dondé y Ramón I. Alcaraz. Cita de Cosmes, Historia, 1901, p. 243. 
Aparentemente, este inicio no era nada favorable a los deseos de Juárez de fortalecer el poder presidencial. Otros acontecimientos vendrían a dar apoyo a su postura.

\section{LAS FACULTADES EXTRAORDINARIAS}

Es cierto que el intento de lograr una concentración de poder en el ejecutivo, mediante las reformas propuestas en la convocatoria del 14 de agosto de 1867 , fracasó; pero ello no fue obstáculo para que esa tenden. cia ganara fuerza a lo largo de toda la república restaurada. Una vez más ese proceso tenía su fundamento en la herencia de la confrontación re. ciente. Como bien resume Cosío Villegas, el país enfrentaba en 1867 una penuria general, serios desajustes sociales, la constitución de una casta militar diferenciada y la vigorosa existencia de una organización caciquil regional, al tiempo que la guerra había generado una tradición de ejercicio de la "autoridad de excepción". Todo ello debía enfrentarse en un clima de libertad política muy amplia, que se manifestaba ante todo en una libertad de prensa irrestricta. ${ }^{28}$

Tenemos entonces como dominantes dos términos en a pariencia antitéticos: la autoridad de excepción y la libertad política. Aunque conviene hacer la aclaración de que esta libertad política y la participación en partidos tenían un carácter limitado, los políticos eran una serie de personalidades, eran "notables" que agrupados

\footnotetext{
${ }^{28}$ Cosío Villegas, República, 1984, p. 77.
}

en torno a determinados proyectos o demandas, constituían los partidos de la época. El sistema de elecciones indirectas de la Constitución del $\mathbf{5 7}$ había promovido este esquema, en el cual la clientela política era manipulada por los gobiernos estatales y las municipalidades, quienes tenían a su cargo los procesos electorales. Por esa razón, ha apuntado Perry, era fundamental el control de esos niveles de gobierno. ${ }^{29}$

Ello fue palpable en los comicios municipales de la ciudad de México de 1871, cuando la división entre Juárez y Lerdo era ya clara. En esa ocasión se formaron dos colegios electorales y dos ayuntamientos reclamaban la legitimidad frente al Congreso. El conflicto coincidió además con el único periodo en que la fracción parlamentaria juarista estuvo en minoría en la Cámara, de tal suerte que por la diferencia de un voto se ordenó al presidente el reconocimiento del ayuntamiento lerdista. Ante esa presión, Juárez no tuvo más remedio que ceder. Sin embargo, el problema no terminó ahí, ya que poco después el gobernador juarista desconoció al poder municipal y, con las protestas de la comisión permanente del Congreso, envió el caso a la consideración de la Suprema Corte..$^{30}$

La libertad política, por otra parte, permitía a los diputados y periódicos porfiristas, en plena lucha contra la revuelta de La Noria, atacar acre y diariamente al régimen, sin problema

29 Perry, "Modelo", 1974, pp. 648 y ss.; Guerra, México, 1988, t. I, p. 192; Rabasa, Evoluctón, 1920, p. 73.

30 Ceballos, Aurora, 1907, pp. 130-131, 136 y 151.152 . 
alguno. ${ }^{31}$ Bajo este ángulo, la existencia de una vida constitucional liberal era indiscutible. Más todavía si agregamos la normalidad de los trabajos del Congreso, y la dureza de los debates que se daban en su seno. El problema es que, como contrapartida de ello, también tenemos la sobrevivencia de la autoridad de excepción, en forma de "facultades extraordinarias" y "suspensión de garantías".

Para enfrentarse a las diversas amenazas a la unidad nacional y a la paz en general-dice Perry-, el presidente pidió y obtuvo del Congreso la suspensión de las garantías constitucionales nueve veces en nueve años, durante un total de 49 meses de los 112 que duró la república restaurada. Además, el presidente tuvo "facultades extraordinarias" todo ese tiempo, excepto 57 días del mismo periodo, que le fueron otorgadas en ocho ocasiones distintas por el Congreso. La modificación más importante del liberalismo, ciertamente, consistió en la suspensión de las garantías constitucionales y en las "facultades extraordinarias" generalmente otorgadas por el Congreso al presidente en los ramos de Hacienda y Guerra. ${ }^{32}$

Cosío Villegas hace un minucioso recuento de las condiciones básicas que permitían ese ejercicio de la autoridad fuera de la Constitución: los levantamientos contra el régimen -de imperialistas, conservadores y liberales excluidos del juego político-, rebeliones agraristas como la de Manuel Lozada, los robos, los plagios y la inse-

31 Cosío Villegàs, República, 1984, p. 283.

32 Perry, "Modelo", 1974, p. 664. guridad existente en un país infestado de hombres armados y lleno de miseria. Pero, como él mismo reconoce, si bien fueron necesarias, esas formas excepcionales de autoridad no se aplicaron continuamente, ni de manera abu. siva, y se "dulcificaron" con el paso del tiempo. Explícitamente hace notar que todo el año de 1869 , de julio a noviem. bre de 1871, y de julio de 1872 a mayo de 1875 , se vivió dentro del régimen constitucional, y que ello representaba sin duda un progreso en el ejercicio de la democracia. En su balance considera que el daño causado por las leyes de excepción no fue tanto interrumpir el reinado de la Constitución, como "el que causaron a la independencia del poder legislativo". 33

Es cierto que el ejecutivo recibió atribuciones especiales para enfrentar la guerra, las sublevaciones y las bandas de ladrones en el campo, y que eso favoreció el "relajamiento constitucional", pero si nos detenemos en esa relación, como Cosmes y Cosío Villegas, es difícil explicarnos que condujera tanto a la pérdida de independencia del legislativo como a la dictadura porfirista. Tenemos que introducir otro elemento fundamental, que es el de la utilización de las facultades ex. traordinarias concedidas al ejecutivo.

Un examen somero muestra que no fueron solamente instrumento para combatir a los enemigos y ladrones, sino para llevar adelante, entre otras cosas, importantes proyectos de desarrollo económico. Un caso concreto fue la concesión para construir el fe-

${ }^{33}$ Cosío Villegas, República, 1984, pp. 346 352.

LOS DILEMAS DE LA DEMOCRACIA 
rrocarril de México a Veracruz, otorgada mediante decreto del 28 de noviembre de 1867 a una compañía inglesa, a pesar de que la misma había mantenido tratos con el imperio. Como además incluía una serie de subvenciones muy favorables a la compañía, los diputados de la oposición impugnaron el decreto. ${ }^{34}$

Las críticas fueron tan severas que José María Iglesias, entonces secretario de Hacienda, tuvo que ir a la Cámara a defender la medida tomada. En primer término justificó la legalidad de las facultades extraordinarias por el "estado de guerra" que vivía el país con Francia, ya que, argumentó, "si bien habían cesado las hostilidades materiales, o sea la lucha armada, el estado de guerra continuaba todavía". Iglesias se extendió en esta argumentación tecnicista de una situación de guerra para apoyar su tesis de que aun cuando las facultades extraordinarias se concedieran por ese motivo, tenían

34 También vale la pena destacar la posición de Lerdo en el asunto, ya que fue clave para que siguiera adelante. Estaba de acuerdo en que para el proyecto ferrocarrilero debía utilizarse capital externo puesto que no había nacional, pero tendría que ser europeo. Según el, no debía permitirse la entrada del capital norteamericano, ni privilegiar las rutas que conectaran con el vecino del norte, ya que eso sería la "vanguardia de la conquista pacífica del país por los Estados Unidos". Esto marca un rasgo diferencial notable respecto del porfirismo. Cosmes, Historia, 1901, pp. 381-382 y 397-398; Garcia Granados, Historia, 1923, pp. 117-118. Además hay que hacer notar que las concesiones previas a empresarios mexicanos, como las que se otorgaron a Antonio Escandón, no habían dado resultados muy exitosos, a pesar de los enormes privilegios que conllevaban. Véase Covo, Ideas, 1983, pp. 455-459. la mayor amplitud, es decir autoriza. ban al ejecutivo para cualquier acto, siempre y cuando no atentara contra la independencia, la integridad del territorio, la forma de gobierno establecida o contra los principios de las Leyes de Reforma. ${ }^{35}$

Si el ejecutivo se preocupaba tanto por obtener de la Cámara tales facultades extraordinarias, y ello generaba debates tan intensos, es porque su uso fortalecía la presencia del presidente en todas las esferas de la actividad estatal. Otro apoyo a esta afirmación se encuentra en la negativa del gobierno juarista de enviar a la Cámara el proyecto de presupuesto federal, como legalmente estaba obligado, a principios de 1868. Su intención oculta era obtener así una prórroga automática de las facultades extraordinarias en materia de Hacienda.

Las consecuencias de ese manejo, en otros terrenos, fueron denunciadas con certeza por el agudo crítico que fue Zamacona:

No creo que el gobierno se complazca en ese caos a que está reducida todavía la Hacienda federal; no creo que los miembros del gabinete desconozcan la conveniencia del método y de las reglas, ni sospecho que quieran explotar el desorden en provecho personal; pero, en el sistema que practican, hay un lamentable error, y es el de creer que, para ciertos fines políticos, es un medio eficaz algo de elasticidad y ensanche en las facultades del gobierno, relativamente al tesoro público. Por ese medio se quiere robustecer el ascendiente 393.

35 Cosmes, Historia, 1901, pp. 387-388 y CÁRDENAS GARCÍA Y ROJAS OIVERA 
personal; y estos intereses, secundarios, pasajeros y mezquinos, se anteponen a los principios del orden y a las prácticas del sistema representativo. ${ }^{36}$

El relajamiento constitucional que vivió la república restaurada no puede atribuirse únicamente a la sobrevivencia de brotes violentos y al bandolerismo, sino también a las necesidades de reordenación de la economía y de las relaciones con el exterior, e incluso al sostenimiento de la autoridad central frente a los fuertes cacicazgos regionales. Un antecedente notable había sido la pugna de Juárez con Vidaurri, misma que llevó al primero a utilizar el ejército, a declarar la desaparición de los poderes en el estado y a decretar la división territorial de Nuevo León y Coahuila (1863-1864). Otros conflictos similares se presentaron después. Lerdo y Vallarta disputaron en 1873 por el control de Jalisco -donde se instalaron nuevamente, como en la ciudad de México en 1871, poderes paralelos-; y el mismo Lerdo tuvo serios problemas con los gobiernos de Coahuila y Yucatán. ${ }^{37}$

\section{LA ELITE DIRIGENTE Y LA LUCHA POLÍTICA}

Tanto los liberales de la época como los historiadores de fines del siglo XIX consultados y algunos estudiosos re-

36 Ibid., pp. 324-325.

37 Scholes, Poltica, 1972, pp. 141-144; García Granados, Historia, 1923, pp. 107 y 128; Rabasa, Constitución, 1956, p. 105. cientes, han acusado a Juárez de alimentar en su régimen una inmovilidad política, puesto que la renovación de los dirigentes estatales no iba más allá de los límites del grupo de fieles conocido como de "Paso del Norte". De ahí pasan a afirmar que ésta fue una de las causas principales de la división de los liberales y de la inestabilidad política del periodo. ${ }^{38}$ Este exclusivismo también se conectaria, según esta crítica, con una tendencia claramente concentradora del poder en el ejecutivo. El corolario sería entonces que primero Díaz, y después Lerdo, pasaron a la oposición solamente por su deseo de alcanzar la presidencia, puesto que Juárez se negaba a dejarla.

Lo primero que parece confirmar esta apreciación es que el régimen juarista haya durado 15 años. Instalado en el poder luego del golpe de Estado de Comonfort en 1857, Juárez permaneció en la silla presidencial hasta su muerte, ocurrida en julio de 1872 . En ese lapso se presentó en tres ocasiones como candidato presidencial (1861, 1867 y 1871), y en otra oportunidad, como hemos visto, simplemente decretó la extensión de su periodo de gobierno (1865). Mas si su estancia en el poder había estado plenamente justificada ante las fuerzas políticas liberales en tiempos de guerra, es decir hasta 1867 , ya no lo pareció tanto en el periodo posterior. Todavía más, la oposición no tenía empacho en reconocer en los comicios de 1867, que su triunfo era necesario para legitimar la

38 Cosmes, Historia, 1901, p. 79; CC ío Villegas, República, 1984, pp. 86-88; Scholes, Política, 1972, pp. 166-167. 
lucha contra la intervención y los actos derivados de ella, entre los que se encontraba el fusilamiento de Maximiliano. Juárez era en ese momento, indiscutiblemente, el símbolo de la nacionalidad amenazada. ${ }^{39}$

En 1871 Juárez ya no tenía ese argumento para permanecer al frente del gobierno. Su nueva justificación parecía ser la de impedir que se frenara la obra de reconstrucción liberal. Por eso fue más difícil su victoria.

Ahora bien, si analizamos los gabinetes de Juárez, salta a la vista que en una primera fase (de 1857 a 1863) su composición fue sumamente variable y heterogénea. Tal vez hubo un núcleo fuerte con Melchor Ocampo, Manuel Doblado, Francisco Zarco, Manuel Ruiz, León Guzmán, Miguel Lerdo de Tejada e Ignacio Ramírez, pero también estuvieron Zamacona, José María Lafragua, Pedro Ogazón, Jesús Terán, Guillermo Prieto y Francisco de Paula y Gochicoa. Ese primer núcleo, con justicia, ha sido llamado el grupo de Veracruz.

En 1863 hay una especie de recambio, con el ingreso de quienes compondrán el grupo de Paso del Norte, y se alcanza mayor estabilidad. Así, Sebastián Lerdo de Tejada estuvo encargado de las relaciones exteriores del 12 de septiembre de 1863 al 17 de enero de 1871, entre septiembre de 1863 y enero de 1868 también fue titular de Gobernación, y en 1872 llegó a la presidencia. Ignacio Mejía, por su parte, ocupó la secretaría de Guerra

39 Véase la opinión de Zarco en Cosío Villegas, República, 1984, pp. 195-196; Cosmes, Historia, 1901, pp. 93-94. desde diciembre de 1865 hasta el 30 de agosto de 1876. José María Iglesias, a su vez, ocupó las carteras de Justicia, Hacienda y Gobernación entre septiembre de 1863 y junio de 1871, y después ocupó la presidencia de la Suprema Corte de Justicia en el cuatrienio de Lerdo. Finalmente, Blas Balcárcel fue titular de Fomento en dos periodos con Juárez, de julio a diciembre de 1861 y de julio de 1867 a julio de 1872, y lo siguió siendo con Lerdo.

Si consideramos que en ese periodo el número máximo de secretarías de Estado fue seis, entonces podemos entender que en verdad el acceso al círculo del ejecutivo estaba limitado. El poco espacio restante lo ocuparon Antonio Martínez de Castro, Manuel Saavedra, Ramón I. Alcaraz, José María Castillo Velasco, Ignacio Vallarta y Ca. yetano Gómez Pérez.

Este recuento ilustra sólo una parte de la elite. La otra estaba en la Cámara de Diputados y en la Suprema Corte, que en este periodo eran poderes reales, independientes del ejecutivo y que en ocasiones limitaron seriamente su poder. ${ }^{40}$ Pero los líderes del Congreso y los ministros pertenecían también a la generación del 57 y la reforma: Lafragua, Ogazón, Montes, Zamacona, Zarco, Altamirano, Guzmán, Mariscal, Ramírez, Riva Palacio, Dondé, Alcalde.

Cuando se perfilo el grupo de oposición "lerdista", sus componentes no eran ajenos a ese círculo. Eran Mariano Escobedo, Romero Rubio, Francisco Mejía, Juan José Baz; quienes

${ }^{40}$ Cosío Villegas, República, 1984, p. 606. 
fueron sus últimos ministros, y lo siguieron hasta el final. 11 Antes de agosto de 1876, Lerdo había gobernado con la maquinaria juarista, lo que reforzó la imagen de continuismo.

Aún más, al enfrentarse Iglesias a Lerdo en 1876, su movimiento decembrista incluyó a Francisco Gómez del Palacio, Prieto, Felipe Berriozábal y Joaquín Alcalde, de tal modo que representaba una renovación muy limitada. ${ }^{42}$

El cambio generacional venía por otra parte. El partido porfirista se había formado desde 1867 sin un proyecto global distinto al juarista. Su bandera de lucha era la Constitución, aun. que pronto se vio que no era más que un parapeto. La revuelta de La Noria mostró que, por el contrario, Díaz era un revolucionario, alguien dispuesto a tomar el poder fuera de los cauces legales, y su derrota de ese momento sólo tuvo el efecto de fortalecer esa postura. En 1876 volvió con el Plan de Tuxtepec y encontró un escenario más favorable: ni Lerdo ni Iglesias estaban mejor amparados por la ley. ${ }^{43}$ Los reformistas habían llegado al final de su época y Díaz podía pretender que representaba "la sustitución de antiguos funcionarios cuya actividad estaba ago-

41 Cosío Villegas, Porfiriato, 1983, p. 117.

12 Ibid, pp. 50-51.

43 "Lo que sucede aquí, señor -decía Esteve en pleno levantamiento tuxtepecano-, es que vemos la democracia amagada, que vemos destruir la base del gobierno por el pueblo, y que lo que se proclama en esos planes de Tuxtepec y Palo Blanco es el gobierno de un solo hombre, es la dictadura de don Porfirio Díaz." Citado en Cosío Villegas, República, 1984, pp. 476-477. tada por el desaliento con otros cuyo vigor estaba intacto". ${ }^{44}$

Si bien provenía del mismo tronco liberal, Díaz no era un hombre del 57 y la reforma, sino de las guerras. Brillante militar pero de alcances limitados, no podía destacar en un sistema donde el poder civil tenía una indiscutible superioridad sobre el militar y el debate era el mecanismo básico de solución de controversias. Su propio grupo encontraba en él escasa orientación política. ${ }^{45}$

Aun así, el recambio generacional no fue tan brusco. Al principio, Díaz tuvo que "usar como elementos estabilizadores a los de la vieja generación, mientras lograba fabricar hombres nuevos y gobernables". ${ }^{46}$ Pero si eso era un signo de continuidad, otros hechos daban cuenta de lo lejos que estaba del respeto fanático de los reformistas por la ley. En su primer periodo de gobierno limitó gradualmente la independencia de la Suprema Corte, creó una eficaz policía política, reprimió con lujo de violencia a los opositores lerdistas cuando ya no representaban peligro alguno y comenzó a conculcar la libertad de prensa. El Federalista, vocero de los lerdistas, sufrió presiones gubernamentales desde agosto de 1877 y tuvo

\footnotetext{
44 Ibid., pp. 57, 105 y 243 . La cita textual es del informe presidencial de 1880 .

is Vease el ilustrativo retrato que Iopez Portillo hace de Díaz. Citado en Cosío Villegas, Porfiriato, 1983, p. 101. Los diputados porfiristas eran comandados por Zamacona y Justo Benítez, véanse Cosmes, Historia, 1901, p. 363 y García Granados, Historia, 1923, pp. 58-59 y 63.

46 Cosío Villegas, Porfiriato, 1983, p. 105.
} 


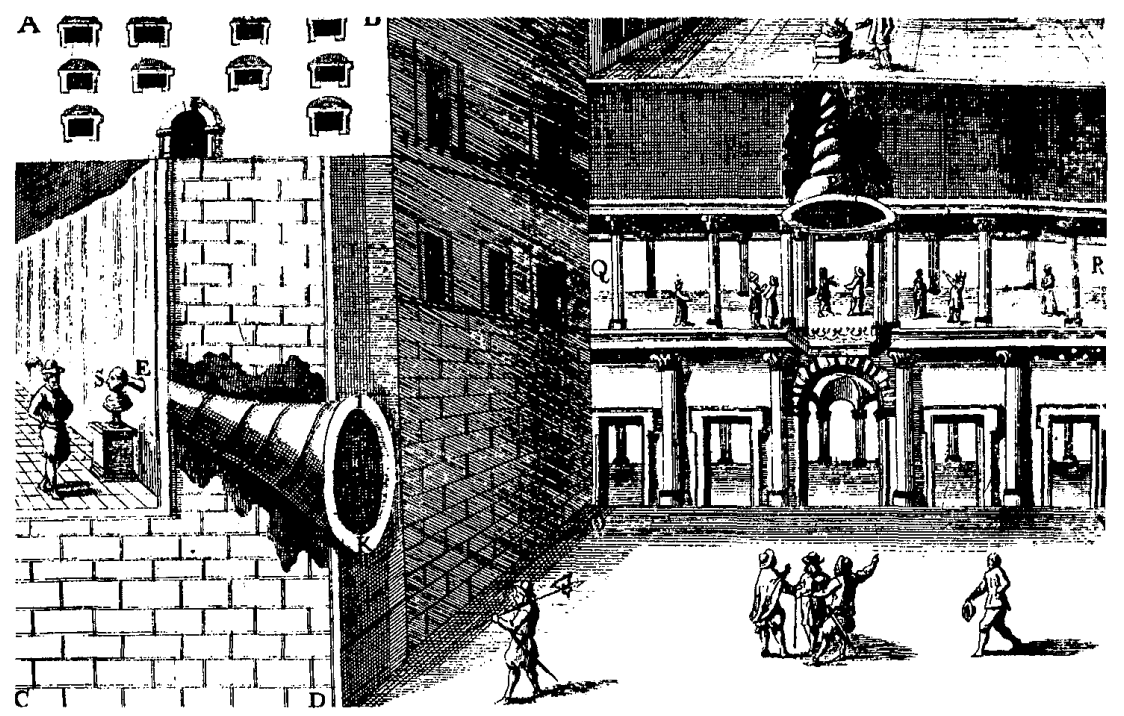

que dejar de publicarse el 31 de octubre de $1878 .{ }^{47}$

Eso contrasta vivamente con la prác. tica política previa, donde el respeto al orden constitucional era su condición básica. La discusión pública, la libertad de prensa, el debate parlamentario y la existencia de fracciones opositoras fuertes, fueron característica de los gobiernos de la república restaurada. La fuerza de la oposición en diversos momentos impuso al gobierno algunas determinaciones. Un buen ejem-

47 Esto es verdad aun si aceptamos que el primer gobierno porfirista esruvo basado en el consenso, y que los rasgos autoritarios del sistema se acentuaron en el periodo de Manuel González. Véanse González, "Dictadura", 1986, pp. 167-169; Cosío Villegas, Porfiriato, 1983, pp. 28-29, 139, 144-145 y 154-155; Rabasa, Evolución, 1920, p. 129. plo fue el control de dos periodos de sesiones del quinto Congreso constitucional (1871) por la mayoría formada con la alianza lerdista/porfirista.

En esa oportunidad un periodo extraordinario de sesiones fue convocado sin el acuerdo del presidente, para discutir un proyecto de ley electoral de la oposición. Sólo gracias a las maniobras de la fracción minoritaria progubernamental no pudo ser aprobado y tuvo que trasladarse al periodo ordinario siguiente. Ahí continuó como el centro del debate, por encima del llamado presidencial a discutir el proyecto de presupuesto. Además, se impugnó al ejecutivo por la utilización de sus facultades extraordinarias en materia de guerra. Finalmente, la alianza opositora pudo hacer aprobar (8 de mayo) la ley sobre liber- 
tad de sufragio, que condenaba la intervención de altos funcionarios de la federación en los procesos electorales (a la que calificaba de "delito oficial"), ordenaba la salida del ejército de los poblados en vísperas de las elecciones, y declaraba inelegibles como diputados a los funcionarios gubernamentales en los distritos de su jurisdicción. ${ }^{48}$

Estos rasgos, si bien generales, ilustran diferencias esenciales entre una y otra generación. Situados en el dilema de fortalecer su control o respetar la ley, Juárez y Lerdo decidieron por lo segundo; Díaz en cambio construyó un gobierno fuerte, que descansaba ante todo en mecanismos informales, en relaciones de clientelismo. Además, pronto olvidó el lema con el cual llegó a la primera magistratura: la no reelección. ${ }^{49}$

\section{CONCLUSIONES}

Ciertamente, tanto Juárez como Lerdo buscaron fortalecer el poder presidencial en sus periodos de gobierno, no sólo para mantener la paz social y el control político, sino también para llevar adelante el proyecto económico liberal. Sin embargo encontraron, en las mismas instituciones liberales que habían construido, un dique que los contuvo. Así Juárez tuvo que hacer un repliegue táctico en su proyecto de reformas a la Constitución, y Lerdo en

48 La lucha en el quinto Congreso puede seguirse en Ceballos, Aurora, 1907, pp. 132134. La ley electoral en pp. 362-363.

49 Falcón, "Desaparición", 1988, pp. 424427; Cosío Villegas, Porfiriato, 1983, p. 188, y Sistema, 1982, p. 15. otro momento tuvo que aceptar fallos adversos de la Suprema Corte presidida por Iglesias. ${ }^{50}$ Los secretarios de Estado, por lo demás, en repetidas ocasiones tenían que presentarse en la Cámara para defender los proyectos gubernamentales y debían mostrar en el debate la justeza de los mismos. Esto es, la disidencia no sólo era posible, sino que se traducía en éxitos políti$\cos$.

Lo característico del juego democrático de la república restaurada no fue la tolerancia, sino la concertación a través del debate público, abierto. Dentro del Congreso hubo una apelación constante a la razón (y a la opinión pública) como fuente de legitimidad. La reconocida capacidad oratoria y polémica de los diputados de las distintas corrientes no era simple adorno de pugnas caudillistas, aun. que se haya entrecruzado con ellas. El debate, para los hombres "políticos" del momento, fue absolutamente real, así como sus efectos. Se trataba de un momento clave en la constitución de un Estado de derecho. ${ }^{51}$

Por otra parte, aceptar que esas estructuras políticas limitaran el cambio socioeconómico tal vez sea conceder mucho al desarrollo posterior. Los valores democráticos liberales cedieron el paso al progreso económico, que bien pronto se identificó con Díaz, pero eso no implica que su exclusión fuera necesaria. Otros factores tuvie-

50 Véase Cosío Villegas, Porfiriato, 1983, pp. 16 y 55, para el amparo concedido por la Suprema Corte a ciudadanos de Morelos contra actos del gobierno estatal.

51 Para una exposición teórica sobre esta cuestión véase Kuhn, "Liberalismo", 1971, p. 83. 
ron para el porfirismo tanta o más importancia: el reconocimiento externo, las inversiones extranjeras, el inicio de la expansión económica norteamericana y un cambio en la tradicional mentalidad especuladora de los empresarios mexicanos.

El ejercicio democrático de la república restaurada, sin embargo, no fue universal, y probablemente no incluyó algo tan importante como el respeto al sufragio. ${ }^{52}$ Esto fundamenta la posición de Guerra, quien ha sugerido que el triunfo de los liberales en México ( $y$ por tanto de los valores ideológicos democráticos), en la medida en que ocurría en una sociedad tradicional, no encontró asidero en ella, y condujo a una "ficción", a la coexistencia de dos entidades ajenas, lo que hizo imposible "una vida política conforme a las instituciones". Esto era así porque los supuestos de igualdad ciudadana, y la manifestación de voluntades individuales que se pronunciaran como tales sobre el interés general, no existían. La realidad sobre la que la elite cultural reformista intentó imponer la Constitución del 57 era arcaica, y estaba cargada de valores y legitimidades tradicionales. En otras palabras, la expansión de la cultura política moderna precedió a la expansión de la economía capitalista, contra lo que había ocurrido en Europa. El pueblo moderno, en esas condiciones, no podía ser más que limitado. ${ }^{53}$

52 Covo, Ideas, 1983, p. 91, nota 120.

53 Guerra, México, 1988, pp. 197-200. Ra. basa, Eeolución, 1920 , p. 244, había planteado ya, con mayor precisión, que el sufragio universal masculino había llevado "por consideracio.
Esta formulación presenta problemas de dos índoles: las relativas al funcionamiento de las instituciones y reglas políticas (la práctica política del sistema), y aquellas que tienen que ver con las relaciones entre ideología y realidad social. Para abordarlas, no está de más recordar que en Europa y no sólo en México:

La democracia liberal se desarrolló en el marco de una sociedad estructurada de forma completamente jerárquica. La formación de la voluntad política quedó limitada de hecho a los estamentos superiores. La base real del Estado liberai no fue nunca un orden de ciudadanos en competencia en igualdad de oportunidades, sino una estructura estable de rangos sociales, asegurada por la formación y la propiedad. 54

Esta práctica excluyente, la búsqueda de una igualdad política formal fundada en una desigualdad real, era clara para los reformistas. Su "pueblo político" no incluía a los campesinos, jornaleros, indios, analfabetos, mujeres, sino a propietarios, profesionistas, periodistas, quienes, desde su punto de vista, podían tener interés funclado en el destino nacional. La clase media ilustrada se reconocía como minoría rectora (representante de la soberanía popular), y a ello respondían, por ejemplo, la estructura política representativa y las elecciones

nes filosóficas, con afrenta de la implacable realidad, a la igualdad absoluta de las masas sociales que no tenían nada de común ni en la vida ni en la conciencia".

54 Habermas cirado en Kuhn, "Liberalismo", 1971, p. 84. 
indirectas. ${ }^{55}$ Para ese pueblo político sí funcionaban las instituciones y era real la democracia.

En cuanto al segundo problema, tal vez sea demasiado tajante la escisión propuesta por Guerra entre ideología democrática y sociedad tradicional. Ambas están inscritas en el mismo mundo real, del que pueden ser partes distintas, pero no totalmente ajenas. Sus fronteras se tocan, en la medida en que la ideología no existe sino en los sujetos sociales.

Por lo demás, la clientela política liberal no terminaba en los periodistas, profesionales, terratenientes, comerciantes y caudillos del norte. También incluía

mucha gente humilde que no pertenecía a la órbita de la Iglesia, o que quería salirse de ella; sobre todo artesanos mestizos, empleados y miembros de las diversas y modestas corporaciones de oficios de las ciudades y pueblos, a los que habría que añadir en la ciudad de México a algunos obreros y artesanos franceses, liberales de avanzada y socialistas expulsados después de la revolución de 1848.56

Ellos representaban esa frontera por la que las prácticas democráticas (y la ideología) podían tener un efecto reproductivo, y por tanto incidencia en la sociedad tradicional.

El régimen de Díaz coartó esas prácticas, y mediante la violencia mantuvo cerrados y ajenos los dos campos (democracia/sociedad) pero, aun

55 Covo, Ideas, 1983 , pp. 110-111, 126, 130 131 y 541 .

56 Chevalier, "Conservadores", 1985, p. 147. así, la sociedad no olvidó el referente teórico ni la escasa experiencia democrática previa. Cuando un miembro indiscutido de ese pueblo político (Madero) recordó en "una presentación más bien árida y algo descuidada" de la historia política reciente, los males derivados del gobierno dictatorial, buena parte de ese pueblo (y de la sociedad tradicional) lo escuchó, le manifestó su adhesión y se levantó en armas. 57

\section{BIBLIOGRAFÍA}

-Cadenhead, Ivie E., Benito Juárez y su época. Ensayo bistórico sobre su importancia, El Colegio de México, México, 1975.

-Ceballos, Ciro, Aurora y ocaso. Ensayo bistórico de política contemporánea, 1867-1906, t. 1, Imprenta Central, México, 1907.

-Chevalier, François, "Conservadores y liberales en México", Secuencia, Instituto de Investigaciones Dr. José María Luis Mora, núm. 1, marzo 1985.

-Coatsworth, John, "Los orígenes sociales del autoritarismo moderno en México", en Leopoldo Allub (coord.), Origenes del autoritarismo en América Latina, Katún, México, 1983.

-Cosío Vilegas, Daniel, Historia moderna de México. El porfiriato. La vida política interior. Parte primera, 2a. ed., Hermes, México, 1983.

, Historia moderna de México.

La república restaurada. La vida política, $2^{\mathrm{a}}$ ed., Hermes, México, 1984.

- El sistema político mexicano. Las posibilidades de cambio, Editorial Joaquín Mortiz, México, 1982.

${ }^{57}$ Cumberland, Madero, 1984, p. 73. 
-Cosmes, Francisco, Historia general de México. Continuación a la de don Niceto de Zamacois. Parte contemporánea. Los últimos 33 años, Ramón de S.N. Araluce Editor, Barcelona, 1901, t. XIX, vol. 21.

-Covo, Jacqueline, Las ideas de la reforma en México (1855-1861), Universidad Nacional Autónoma de México, México, 1983.

-Cumberland, Charles, Madero y la revolución mexicana, Siglo XXI Editores, México, 1984.

-Falcón, Romana, "La desaparición de jefes políticos en Coahuila. Una paradoja porfirista", Historia Mexicana, El Colegio de México, vol. xxxvi, núm 3 (147), eneromarzo 1988.

- "Logros y límites de la centralización porfirista. Coahuila vista desde arriba", en Anne Staples, Romana Falcón, et al., El dominio de las minorias. República restaurada y porfiriato, El Colegio de México, México, 1989.

-García Granados, Ricardo, Historia de México. Desde la restauractón de la república en 1867, hasta la caída de Porfirio Diaz, Andrés Botas e hijos, México, 1923, t. 1 .

-González, Luis, "La dictadura de Díaz", en Julio Labastida (coord.), Dictaduras $y$ dictadores, Siglo XXI Editores, México, 1986.

-González Casanova, Pablo, El Estado y los partidos políticos en México, Era, México, 1985.

-Guerra, François-Xavier, México: del antiguo régimen a la revolución, Fondo de Cultura Económica, México, 1988, 2 vols.
-Krauze, Enrique, Por una democracia sin adjetivos, Joaquín Mortiz/Planeta, México, 1990.

-Kuhn, Reinhard, "El liberalismo", en Wolfgang Abendroth y Kurt Lenk, Intmoducción a la ciencia política, Anagrama, Barcelona, 1971.

-Meyer, Jean, "El ocaso de Manuel Lozada", Historia Mexicana, El Colegio de México, vol. xvill, núm. 4 (72), abril-junio 1969.

-Perry, Laurens B., "El modelo liberal y la política práctica en la república restaurada. 1867-1876", Historia Mexicana, El Colegio de México, vol. XxIII, núm. 4 (92), abriljunio 1974.

-Rabasa, Emilio, La constitución y la dictadura. Estudio sobre la organización política de México, Editorial Porrúa, México, 1956. , La evolución bistórica de México, Librería de la Vda. de Ch. Bouret, México, 1920.

-Staples, Anne, Romana Falcón, et al., El dominio de las minorias. República restaurada y porfiriato, El Colegio de México, México, 1989.

-Scholes, Walter V., Política mexicana durante el régimen de Juárez. 1855-1872, Fondo de Cultura Económica, México, 1972.

-Verduzco, Gustavo, "Zamora en el porfiriato: una expresión liberal de los conservadores", en Anne Staples, Romana Falcón, et al., El dominio de las minorías. República restaurada y porfiriato, EI Colegio de México, 1989.

-Walker, David W., Parentesco, negocios y polífica. La familia Martínez del Río en México, 1823-1867, Alianza Editorial, México, 1991. 